\title{
A COMPARATIVE STUDY OF OVERLAY AND UNDERLAY MYRINGOPLASTY CONSIDERING CLOSURE OF PERFORATION AND HEARING RESULTS: OUR EXPERIENCE
}

\author{
Arumugam I1, Kannappan $A L^{2}$, Rizwan Rafeeque $M^{3}$
}

1 Professor \& HOD, Department of ENT, Vinayaka Missions Medical College and Hospital.

2Post Graduate, Department of ENT, Vinayaka Missions Medical College and Hospital.

${ }^{3}$ Post Graduate, Department of ENT, Vinayaka Missions Medical College and Hospital.

\begin{tabular}{l}
\hline ABSTRACT \\
\hline BACKGROUND \\
Myringoplasty is an established procedure for closure of tympanic membrane perforations. The quest is on to improve the results \\
further by studying various technique.
\end{tabular}

\section{METHODS}

In the present randomized prospective study of one-year duration, 103 patients having a dry large or a subtotal perforation were subjected to myringoplasty by overlay ( 51 cases) and underlay (52 cases) techniques.

\section{RESULTS}

The underlay technique resulted in a $94.2 \%$ (49 cases) success rate in comparison with overlay technique in a success rate of 91.5\% (46 cases).

\section{CONCLUSION}

From this study we understand that the technical ease, better ossicular judgement, hearing results and healing were found to be better in underlay technique.

\section{KEYWORDS}

Myringoplasty, Hearing Results, Underlay Myringoplasty, Overlay Myringoplasty.

HOW TO CITE THIS ARTICLE: Arumugam I, Kannappan AL, Rafeeque RM. A comparative study of overlay and underlay myringoplasty considering closure of perforation and hearing results: our experience. J. Evolution Med. Dent. Sci. 2016;5(31): 1635-1637, DOI: $10.14260 /$ jemds/2016/385

\section{INTRODUCTION}

Perforation of the tympanic membrane primarily results from middle ear infections, trauma and rarely due to iatrogenic causes. Up to $80 \%$ of these perforations heal spontaneously.[1] The remaining that do not heal and require a surgical repair known as myringoplasty. The technique was introduced by Berthold.[2] Myringoplasty was further developed by Wullstein.[3] and Zollner.[4] Myringoplasty is a procedure, which deals on repair of the tympanic membrane. This procedure can be done through various routes (i.e.) Postaural, Endaural and Endomeatal. Various grafts are available such as temporalis fascia, vein graft, perichondrium which can be used. The technique can be categorized as underlay, overlay or interlay depending on the placement of the graft material.

Several factors may affect surgical outcome. They are the surgical approach (Endaural, Postaural) and technique (Underlay vs. Overlay), site of perforation and type of graft utilized.

The surgical technique of which is better is still a matter of debate. The two classical techniques that have been developed are the "Underlay" and the "Overlay" procedures. Another variety of Interlay has also been proposed.

Financial or Other, Competing Interest: None.

Submission 01-03-2016, Peer Review 13-03-2016,

Acceptance 16-03-2016, Published 16-04-2016.

Corresponding Author:

Dr. Kannappan $A L$

No. 1, 2 ${ }^{\text {nd }}$ Cross Street,

Pudhu Nagar, Keezhakasakuddy,

Kottucherry Post,

Karaikal-609609.

E-mail: kannacoolguy317@gmail.com

DOI: $10.14260 /$ jemds $/ 2016 / 385$
Technique wise, overlay myringoplasty was not giving consistent results. It may be due to a number of reasons, especially when the perforation is more anteriorly placed. In the year 1960, Shea and Tabb.[5-7] introduced the concept of placing the graft material medial to the remnants of the drum. Underlay myringoplasty is widely used and relatively simple to perform. In this technique, the graft is placed entirely medial to the remaining drum and malleus. This technique is ideal to repair small and easily visualized perforations.

Complications like blunting and lateralization of the graft are avoided and the drum heals at the correct level relative to the annulus. On the other hand, its disadvantages are that the middle ear space is reduced and adhesions may occur. Exposure of the middle ear is relatively limited and it is not the ideal technique for perforations extending into the anterior annulus since placement of the graft is difficult. In contrast, the overlay technique is more challenging and typically reserved for total perforations and anterior perforations. In the overlay technique, the graft is placed lateral to the annulus and any remaining fibrous middle layer after the squamous layer is carefully removed.

In this technique, there is an excellent visualization of the anterior meatal recess, which is important in cases of anterior perforations. In addition, the healing rate is high, because the drum is essentially replaced intact and the middle ear space is not reduced. The most serious disadvantages are blunting of the anterior meatal recess and lateralization of the graft. Some also report iatrogenic cholesteatoma in this technique. Moreover, this technique is more laborious and the healing time is longer. ${ }^{[8]}$ However, there is still uncertainty about the prognostic factors in myringoplasty. 
There are significant variations in the reported success rates for achieving an intact tympanic membrane after surgery.

\section{MATERIALS AND METHODS}

1. This is a prospective study performed in the Department of E.N.T. Vinayaka Missions Medical College, Karaikal.

2. Study Period: Patients attending the E.N.T. O.P.D. of Vinayaka Missions Medical College Hospital during the period from April 2014-June 2015.

3. Sample Size: Total 103 patients.

\section{Inclusion Criteria}

1. Age: 15 to 60 years.

2. Dry Central Perforation with Duration of Minimum 6 Weeks.

3. Normal Eustachian Tube and Cochlear Function.

\section{Exclusion Criteria}

1. Cholesteatoma.

2. Granulation tissue of Middle Ear.

3. Tympanosclerosis.

4. Ossicular Chain Disorders.

5. Revision or Combined Procedures, e.g. Mastoidectomy and Ossiculoplasty.

Cases selected for study were subjected to detailed history and clinical examination. Patients were prepared for surgery under general anaesthesia.

Informed consent was obtained from the patients meeting the inclusion criteria. In our study, postaural approach was used in all patients. Depending on the placement of the graft material, this study compares underlay and overlay techniques of myringoplasty procedure. In overlay technique, the graft material was placed over the fibrous layer of membrane remnant. In underlay technique, the graft material was placed under the membrane remnant including the flap after elevating the tympanomeatal flap beyond the annulus.

We treated 103 ears in a general population of 55 female patients and 48 male patients with a median age of 36.2 years (Range 15-60 years). The cause of perforation was infection in 92 cases and trauma in the remaining 11 patients. All the ears at the time of surgery were dry.

The underlay technique was used in 52 patients (24 males, 28 females) with age ranging from 15 to 60 years (Mean 33.4). The primary causes of disease were infection ( 47 cases, $88.5 \%$ ) and trauma (5 cases, $11.5 \%$ ). The right ear was involved in 30 cases and the left ear in the remaining 22 patients. In relation to the handle of the malleus, perforation was noted in the posterior ( 21 ears, $40.4 \%$ ), postero-inferior (12 ears, $23.0 \%$ ), anterior ( 6 ear, $11.5 \%$ ), postero-superior ( 4 ears, 7.7\%), antero-inferior (4 ears, 7.7\%), inferior (3 ears, $5.7 \%$ ) and superior (2 ears, 3.8\%) parts of the tympanic membrane.

The overlay technique was used in 51 patients ( 24 males, 27 females) with age ranging from 15 to 60 years (mean 38.5). The leading causes of disease were infection ( 45 cases) and trauma ( 6 cases). In 8 patients, we performed a revision surgery for a residual perforation. The right ear was involved in 26 cases and the left ear in the remaining 25 subjects. In relation to the handle of the malleus, perforation involved more than $50 \%$ of the tympanic membrane (Sub-total) in 27 ears $(42.8 \%)$ and was noted in the antero-inferior (11 ears, $17.4 \%$ ), anterior ( 7 ears, $11.1 \%$ ), posterior (5 ears, $40.4 \%$ ); four patients were lost to follow-up and were not included in the analysis.

The patients were advised to avoid straining and forceful nose blowing postoperatively. The first post-operative followup to be done at the end of 2 weeks. Subsequent followups to be done at 4 weeks, then at monthly interval for first 6 months. At each visit, microscopic ear examination and tuning fork tests were performed. Post-operative pure tone audiometry was done 6 months after the operation and the functional outcome of both procedures was calculated by estimating the diminution (If any) in the amount of the air bone gap postoperatively at frequencies $0.5,1$, and $2 \mathrm{kHz}$.

\section{RESULTS}

A total of 103 patients were treated. The underlay technique resulted in a $94.2 \%$ (49 cases) success rate: postoperative perforation was noted in three cases; in all three patients, the perforation involved the anterior parts of the tympanic membrane.

The pre-op mean air bone gap was found to be $19.9 \mathrm{~dB}$ Post-operatively mean air bone gap was reduced to $9.3 \mathrm{~dB}$. The overlay technique resulted in a $91.5 \%$ (46 cases) success rate: postoperative perforation was noted in five cases; in three patients the perforation was subtotal and in the remaining two it involved the antero-inferior part of the tympanic membrane. In this group, we noted an anterior blunting and/or a graft lateralization in 4 cases. The pre-op mean air bone gap was found to be $22.3 \mathrm{~dB}$. Post-operatively, mean air bone gap was reduced to $14.6 \mathrm{~dB}$.

\begin{tabular}{|c|c|}
\hline Technique & Number of Patients \\
\hline Overlay & 51 \\
\hline Underlay & 52 \\
\hline \multicolumn{2}{|c|}{ Table 1 } \\
\hline
\end{tabular}

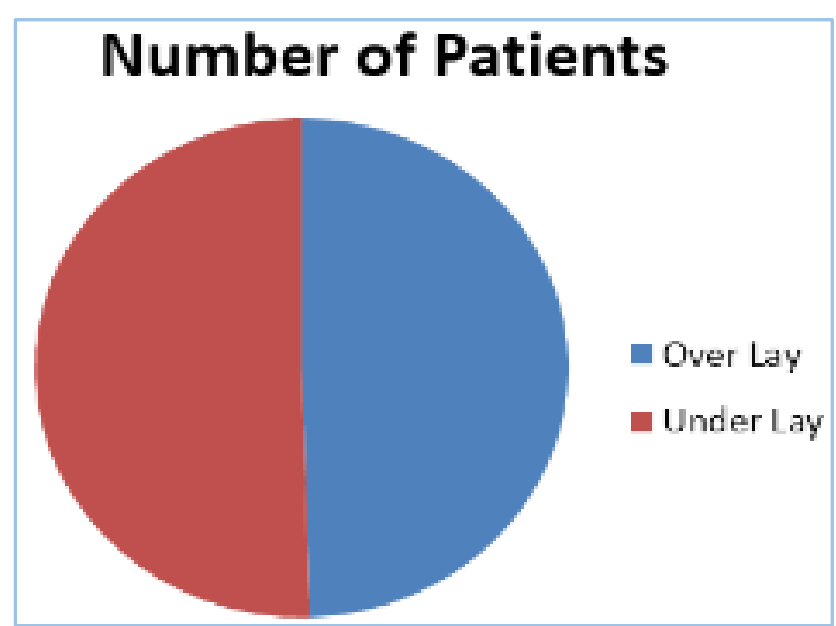

\begin{tabular}{|c|c|c|}
\hline Technique & $\begin{array}{c}\text { Pre-op AB Gap } \\
\text { (Mean) }\end{array}$ & $\begin{array}{c}\text { Post-op AB Gap } \\
\text { (Mean) }\end{array}$ \\
\hline Overlay & $19.9 \mathrm{~dB}$ & $9.3 \mathrm{~dB}$ \\
\hline Underlay & $22.3 \mathrm{~dB}$ & $14.6 \mathrm{~dB}$ \\
\hline \multicolumn{2}{|c|}{ Table 2: Pure Tone Audiometry Results } \\
\hline
\end{tabular}




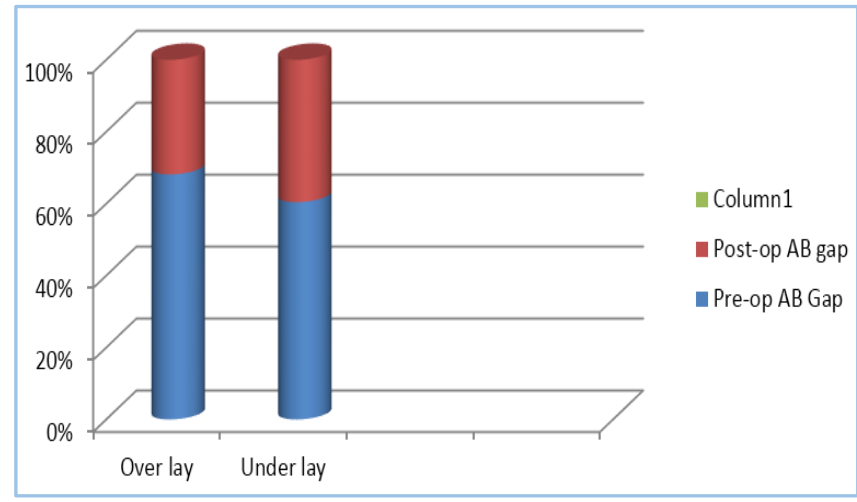

\section{DISCUSSION}

Myringoplasty (Type 1 tympanoplasty) is a surgical procedure of reconstruction that is limited to repairing tympanic membrane perforation. The main objective of myringoplasty has been the closure of the tympanic membrane perforation to prevent chronic infections and make the ear safe.[9] The other objective of the procedure is to improve the hearing loss, which had resulted due to perforation of the tympanic membrane. There is still no consensus about the optimal technique of which is to be employed. The selection of procedure is based on surgeon's preference and skills and not on the type of the tympanic membrane perforation. ${ }^{[10]}$ All the patients included in our study were divided into two groups.

It is based on the technique utilized to repair the tympanic membrane perforation. When we compared overlay technique with underlay technique, it was observed that there was no statistically significant difference between these two techniques. In this study, the outcome in terms of graft uptake rate was slightly better in the underlay technique (94.2\%) as compared to the overlay technique $(91.5 \%), \mathrm{P}>0.05$ which was similar to those reported in literature by Crovetto De La Torre et al.[11] and Mishra et al.[12] The results of this study is better than Ashfaq et al.[13] They reported a graft uptake rate of 73\% with underlay technique in 105 cases and Khan and Khan.[14] who reported $77.5 \%$ graft success rate in 94 cases using the same technique. These were also better than Fadl.[15] who had $85.4 \%$ success rate with underlay technique series and $66.7 \%$ success in the overlay technique.

The onset of complications was not significantly different between overlay and underlay techniques. We observed a longer healing time in the overlay group, which was probably due to the surgical manipulation. It also had led to the development of a larger amount of granulation tissue.

Our study was in contrast with other series, in that.[5,6] with use of overlay technique, anterior blunting, graft lateralization, thickening of the drum, iatrogenic cholesteatoma or post-inflammatory ear canal stenosis was not observed. The good results of overlay technique is attributed to the post-auricular approach. The other reason attributed to success was adequate drilling of the bone of the external auditory canal, especially when there was an anterior bulge which improved the exposure of anterior remnant and thus preventing the anterior blunting.

The tympanic membrane remnant and the skin of the ear canal is always removed that could cause epithelial pearls or in future may develop iatrogenic cholesteatoma. The fascia is placed exactly onto the bony annulus after having obtained a good haemostasis. It should be placed just a little overriding onto the canal wall and it is anchored to the malleus to avoid lateralization. Finally, the ear canal is packed from the anterior part with narrow strips of Gelfoam $\AA$ to reinforce the anterior aspect of the ear drum. The high success rate is achieved with the underlay technique.

It is probably due to the reduced surgical manipulation of middle ear structures and faster healing, which minimizes further complications. Patient selection may also have had a role in the high success rate. We excluded patients with severe disease presenting in the mastoid or those requiring ossiculoplasty.

\section{CONCLUSION}

From the results of this study, it is concluded that underlay technique is more successful as compared to overlay technique of myringoplasty, both in children and adults. It is a better technique because of its high rate of graft uptake, technical ease, better hearing results, ability to assess ossicular chain, less time consumption and minimal complications.

\section{REFERENCES}

1. Galdstone HB, Jackler RK, Varav K. Tympanic membrane wound healing. An overview. Otolaryngol Clin North Am 1995;28(5):913-32.

2. Berthold E. Ueber myringoplastik. Wier Med Bull 1878;1:627.

3. Wullstein H. Theory and practice of myringoplasty. Laryngoscope 1956;66:1076-93.

4. Zollner F. The principles of plastic surgery of the soundconducting apparatus. J Laryngol Otol 1955;69(10):63752.

5. Aggarwal R, Saeed SR, Green KJ. Myringoplasty. J Laryngol Otol 2006;120(6):429-32.

6. Shea JJ. Vein graft closure of ear drum perforation. J Laryngol Otol 1960;74(6):358-62. doi: $10.1017 / \mathrm{S} 002221510005670$.

7. Tabb HG. Closure of perforation of tympanic membrane by vein grafts. Laryngoscope 1960;73:699.

8. Tabb HG. Experience in transcanal and post auricular myringoplasty. Tran Pac Coast Oto Ophthalmol Soc Arnn Meet 1968;52:121-5.

9. Sergi B, Galli J, De Corso E, et al. Overlay versus underlay myringoplasty: report of outcomes considering closure of perforation and hearing function. Acta Otorhinolaryngol Italy 2011;31(6):366-71.

10. Labatut Pesce T, Sierra Grañon C, Mora Rivas E, et al. Primary myringoplasties. Results after a 2 year follow-up period. Acta Otorrinolaringol Esp 2009;60(2):79-83.

11. Crovetto De La Torre M, Fiz Melsió L, Escobar Martínez A. Myringoplasty in chronic simple otitis media. Comparative analysis of underlay and overlay techniques. Acta Otorrinolaringol Esp 2000;51(2):101-4.

12. Mishra P, Sonkhya N, Mathur N. Prospective study of 100 cases of underlay tympanoplasty with superiorly based circumferential flap for subtotal perforations. Indian J Otolaryngol Head Neck Surg 2007;59(3):225-8.

13. Ashfaq M, Aasim MU, Khan N. Myringoplasty: anatomical and functional results. Pak Armed Forces Med J 2004;54:155-8.

14. Khan IZ, Khan MA. Tympanoplasty at combined military hospital Rawalpindi. Pak Armed Forces Med J 1995;45:335.

15. Fadl FA. Outcome of type-1 tympanoplasty. Saudi Med J 2003;24:58-61. 